\title{
Design of Optimal Controller for the Conical Tank System
}

\author{
P. Naveen kumar ${ }^{1}$,T.Anitha ${ }^{2}$ \\ PG Student, Sri Ramakrishna Engineering College, Department of Control and Instrumentation, Coimbatore, India ${ }^{1}$ \\ Assistant Professor, Sri Ramakrishna Engineering College, Dept. of Control and Instrumentation, Coimbatore, India ${ }^{2}$
}

\begin{abstract}
The control is the main process in industries in that liquid level control plays important role in many industries like petroleum, food manufacturing etc. Many process industries use conical tanks because it prevents the accumulation of solid at the bottom of the tank. The non-linearity and constantly changing cross section of the conical tank are the immense challenge in control in process industries and it cannot be controlled by the linear Proportional Integral Derivative (PID) controllers. The Proportional-Integral (PI) controller is commonly used to control the level in process industries. Tuning of the PI gain parameters is setting the proportional, integral constant to get the best control of the process. The standard controller tuning methods are the Ziegler Nichols (Z-N) and Cohen-Coon methods. Most of the industries using PID controller for controlling the process so the PID controller wants to tuned to get a better performance, for that optimal selection of PID controller using particle swarm optimization technique is used in this project and also the Z-N tuned PI controller, IMC controller are designed for the Conical Tank System (CTS) and simulated using MATLAB/SIMULINK environment. From the simulation results it has been proved that the optimal controller gives good control system performance than other controllers.
\end{abstract}

Keywords: Conical tank, Piecewise Linearization, Optimal Controller.

\section{INTRODUCTION}

Control of level is a challenging task for several reasons due to their nonlinear dynamic behaviour and time varying parameters, interaction between manipulated and controlled variables and frequent interaction, dead time on input and measurements. The control of liquid level and flow is a basic problem in process industries so control of level is an important and common task in process industries. The PI and PID controllers are mainly used in many industrial process control because of its easy design structure. When it controls of nonlinear and multivariable processes, the controller parameters have to be adjusted continuously. In this project the transfer function of the tank is obtained by using piecewise linearization method in open loop response of conical tank in real time. The Z$\mathrm{N}$ tuned PI controller, IMC controller, and PI controllers with PSO optimized parameters are designed and simulated using MATLAB environment and the results in the simulation is compared. The setup of the conical tank system is given below in Fig 1,

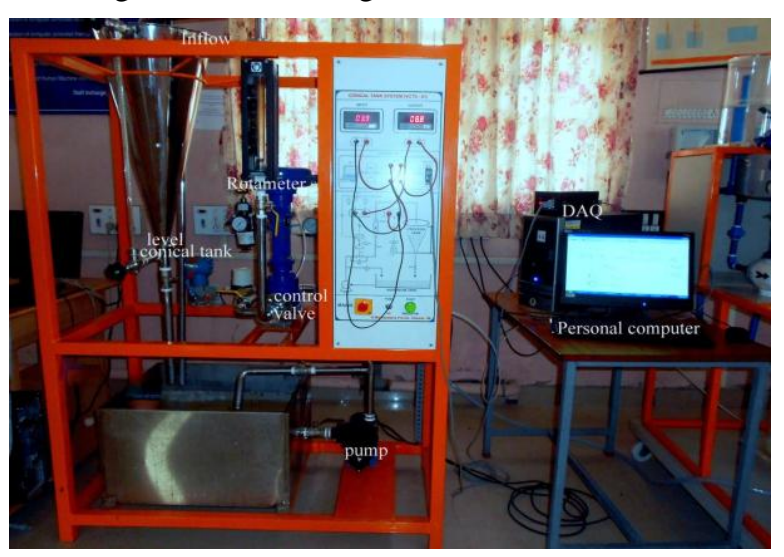

Fig. 1. Experimental setup of conical tank control system
The conical tank system is made up of steel and is placed vertically on the standpoint. The water arrives into the tank from the top and leaves towards the basin, which is placed at the end of the tank. The level of the liquid in the conical tank is measured by using the Differential Pressure Transmitter. The measured level of water is taken as the current value in the range of (4-20) $\mathrm{mA}$ is sent to the Data Acquisition in which ADC changes the analog data into digital data and send it to the PC. The PC acts as the controller as well as the data logger. The controller takes the process variable as feedback signal and finds the output based on the control algorithm. The DAC module of the DAQ converts this manipulated variable to analog form into 4-20 mA current signal. The I/P converter converts the current value to pressure in the range of (3-15 psi), which regulates the flow of water into the conical tank system based on the outflow rate of the tank.

\section{PIECEWISE LINEARIZATION}

Piecewise linearization is the method of linearizing the system in a piecewise, this method is done in open loop real time process, here the response is splitted into four regions and for each region the transfer function is obtained using process reaction curve method.

The process steady state input output characteristics thus obtained shows the non-linear characteristics as the zone varies in a non-linear fashion with the process variable height. To obtain a linear model steady state input - output characteristics curvature is divided into four dissimilar linear sections.

The Response for piecewise linearization shown in the Fig 3. 


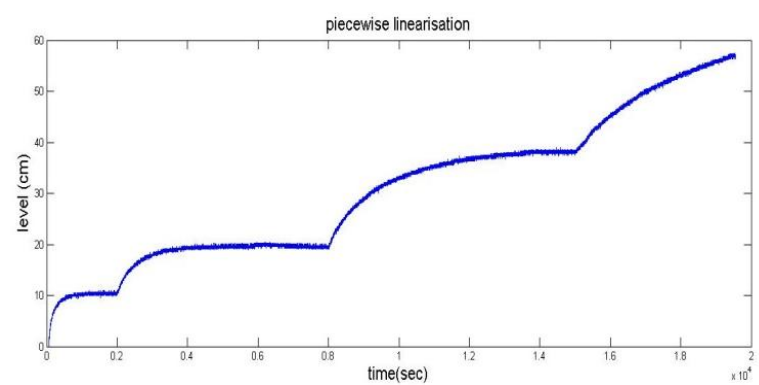

Fig. 3.Simulink response of piecewise linearization

To obtain a linear model steady state input - output characteristics curvature is divided into four dissimilar linear regions.

The transfer functions obtained for the four regions are shown in the Equations (1), (2), (3) and (4).

Zone I (0 to $10.46 \mathrm{~cm})$

$$
G_{1}(s)=\frac{0.0469 e^{-30 s}}{174.98 s+1}
$$

Zone II (10.46 to $19.56 \mathrm{~cm})$

$$
G_{2}(s)=\frac{0.0756 e^{-26 s}}{601.96 s+1}
$$

Zone III (19.56 to $37.98 \mathrm{~cm})$

$$
G_{3}(s)=\frac{0.119 e^{-24 S}}{1160.8 s+1}
$$

Zone IV (37.98 to $57.09 \mathrm{~cm})$

$$
G_{4}(s)=\frac{0.1241 e^{-19 s}}{496.92 s+1}
$$

In piecewise linearization four step inputs are given for four different zones. But the flow rate and the time is given one after another. Hence while the process is run it will settle before the time given in first step input is elapsed.

Once it reaches the time after settling then it goes to the second region. Similarly the process is repeated for all zones and response is obtained. The flow rate and the corresponding steady state are shown in the Table 1.

Table. 1. Flow rate and corresponding steady state values

\begin{tabular}{|c|c|c|c|}
\hline Zone & $\begin{array}{c}\text { Flow } \\
\text { Rate (lph) }\end{array}$ & $\begin{array}{c}\text { Time Taken } \\
(\mathbf{s e c})\end{array}$ & $\begin{array}{c}\text { Steady State } \\
\text { Level }(\mathbf{c m})\end{array}$ \\
\hline 1 & 220 & 2000 & 10.42 \\
\hline 2 & 260 & 6000 & 19.56 \\
\hline 3 & 320 & 11000 & 37.98 \\
\hline 4 & 400 & 16000 & 57.09 \\
\hline
\end{tabular}

\section{CONTROLLER DESIGN}

\section{A. PI Controller}

Currently, most of the process industries uses PI controller for the best performance. In the past, many of these controllers remain analog. Still, many of today's controllers use digital signals. When a mathematical model of a system is existing, the constraints of the controller can be clearly determined. However, when a mathematical model is unreachable, the parameters must be determined experimentally.

The PI controller consists of proportional and integral term. The proportional term modifies the controller output proportional to the current error value. Huge values of proportional time make the system unstable. The Integral time varies the controller output based on the past values of error. So, the controller tries to minimize the inaccuracy by regulating the controller output. The PI gain values are calculated by using the Cohen and Coon open loop tuning algorithm. PI Controller can expressed by the Equation (5),

$$
u(t)=K_{C}\left(e(t)+\frac{1}{T_{i}} \int_{0}^{t} e(t) d t\right)
$$

$\mathrm{u}(\mathrm{t})$ is the control signal

$\mathrm{e}(\mathrm{t})$ is the difference between the current value and the set point.

$\mathrm{K}_{\mathrm{c}}$ is the gain for a proportional controller.

$T_{i}$ is the parameter that scales the integral controller.

$\mathrm{t}$ is the time taken for error measurement.

Controller fine-tuning is the process of defining the controller constraints which yields the desired output. Controller tuning permits for optimization of a process and reduces the inaccuracy among the variable of the process and its set point.

The most common classical controller tuning methods are the ziegler-nichols and cohen-coon methods. The zieglernichols technique can be used for both closed and open loop schemes, while Cohen-Coon is classically used for open loop systems. A closed-loop control system is a scheme which uses feedback control. In an open-loop system the output is not equated to the input.

\section{a. Z-N Tuning}

This technique remains a standard technique for finetuning controllers that use proportional, integral, and derivative actions. The controller constraints can be tuned using Cohen and Coon or Ziegler Nichol's technique. The ziegler-nichols open-loop method is similarly denoted as the process reaction method, because it tests the open-loop reaction of the process to modify in the control variable output. This simple test requires that the response of the system be recorded, preferably by a computer. Once assured process response values are found, they can be worked into the ziegler-nichols calculation with exact multiplier constants for the improvements of the controller with either P, PI, or PID actions.

Z-N open loop tuning formula for PI controller is specified in the Equations (6) and (7).

$$
\begin{aligned}
K_{p} & =\frac{0.09 \tau}{k t_{d}} \\
K_{I} & =\frac{k_{P}}{\tau_{I}} \\
\tau_{I} & =3.33 t_{d}
\end{aligned}
$$


INTERNATIONAL JOURNAL OF INNOVATIVE RESEARCH IN ELECTRICAL, ELECTRONICS, INSTRUMENTATION AND CONTROL ENGINEERING Vol. 4, Issue 2, February 2016

$\mathrm{K}_{\mathrm{P}}=$ Proportional gain

$\mathrm{K}_{\mathrm{i}}=$ Integral gain

$\mathrm{T}_{\mathrm{i}}=$ Integral time

$t_{d}=$ Delay time

For the nonlinear system using the single transfer function for setpoint $10 \mathrm{~cm}$, the PI gain values can be calculated. The transfer function obtained is given by the Equation (8),

$$
G_{1}(s)=\frac{0.0469 e^{-30 s}}{174.98 s+1}
$$

The calculated PI gain parameters can be given as

$\mathrm{K}_{\mathrm{p}}=9.604$

$\mathrm{K}_{\mathrm{I}}=0.11$

\section{B. Internal Model Controller (IMC) \\ a. Introduction}

In process control, Internal model control systems is mainly used to get the desired set points and reject small external troubles. The internal model control (IMC) scheme is based on the fact that control system holds some illustration of the process to be controlled then a faultless control can be attained. So, if the control design has been established based on the precise model of the process then faultless control is mathematically possible, the IMC basic structure is given below in Fig 4.

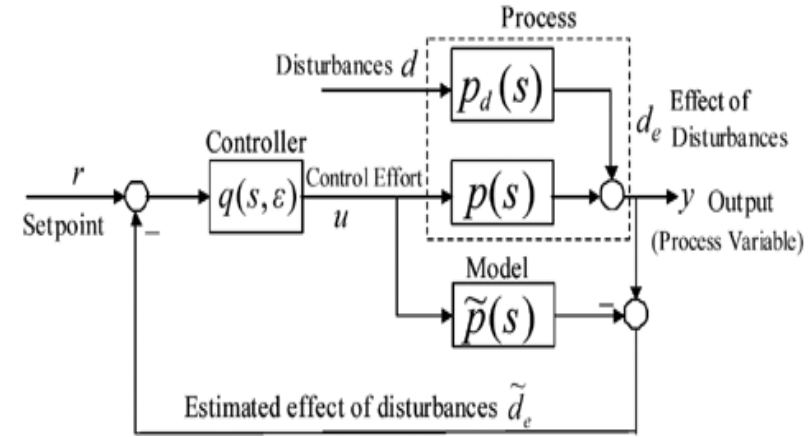

Fig. 4. IMC basic structure

\section{b. Practical Design of IMC}

IMC is designed for the conical tank system by the transfer function given in Equation (9),

$$
G_{1}(s)=\frac{0.0469 e^{-30 s}}{174.98 s+1}
$$

Equation (9) is the transfer function for the setpoint $10 \mathrm{~cm}$ , from this IMC is designed by the given Equation (10)

$$
\mathrm{G}_{\mathrm{IMC}}(\mathrm{s})=\mathrm{G}_{\mathrm{c}}(\mathrm{s}) \mathrm{G}_{\mathrm{f}}(\mathrm{s})
$$

Where

$$
\begin{aligned}
& \mathrm{G}_{\mathrm{c}}(\mathrm{s})=\text { Inverse of } \mathrm{G}_{\mathrm{P}}(\mathrm{s}) \\
& \mathrm{G}_{\mathrm{f}}(\mathrm{s})=\text { Low Pass Filter }
\end{aligned}
$$

The transfer function of the low pass filter is given below

$$
G f(s)=\frac{1}{\tau s+1}
$$

Assume $\tau=10$

With these parameters the final transfer function of IMC is expressed in Equation (10)

$$
G(s)=\frac{174.98 s+1}{0.7504+0.0469}
$$

\section{Optimal Controller (PSO)}

Optimal selection of PI controller constraints using particle swarm optimization method for controlling level in conical tank system is presented. The particle swarm optimization (PSO) approach has stable convergence characteristics, easy implementation, superior features and good computational performance efficiency.

\section{a. PI-PSO controller for single loop control}

In this section, to find the optimal gain parameters of the PI controller for the conical tank system, the Particle Swarm Optimization algorithm is used. Fig 5 shows the structure of the PI controller with PSO algorithm.

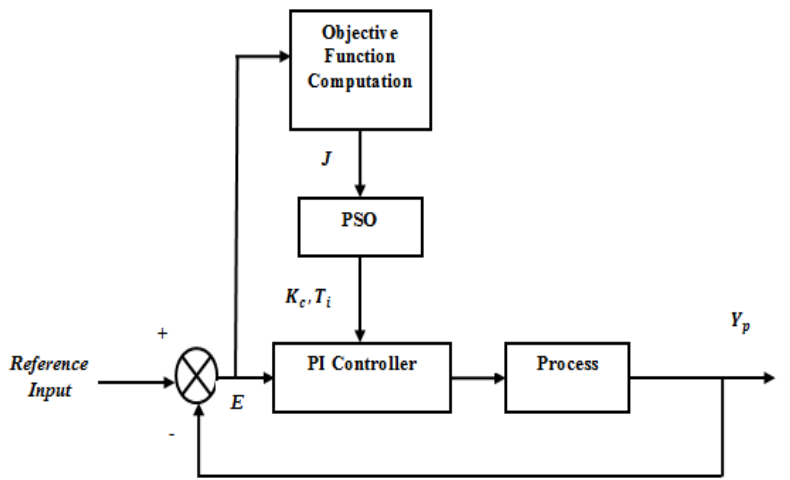

Fig. 5.Block diagram of PI-PSO controller for single loop control

In the suggested PSO method each particle has two members $\mathrm{P}$ and I which means that the search space has two aspect and features must 'fly' in two dimensional space. The PSO-PI controller algorithm for choosing the best optimal gain values of $\mathrm{K}_{\mathrm{c}}$ and $\mathrm{K}_{\mathrm{i}}$ of the system is shown in figure. The optimization steps are represented as flow chart given below in Fig 6 .

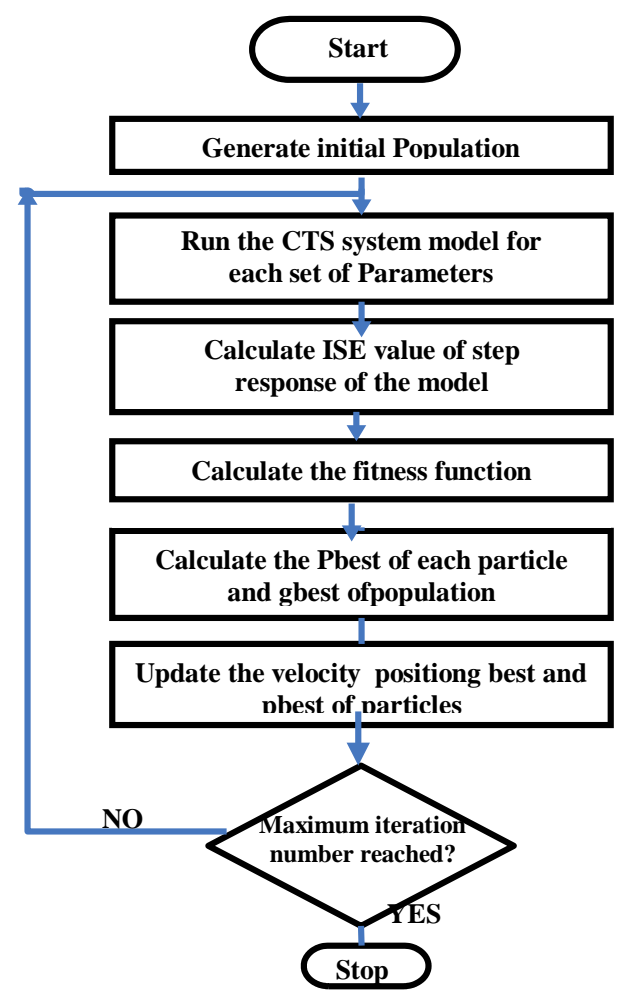

Fig. 6. Flow chart for PSO algorithm 
INTERNATIONAL JOURNAL OF INNOVATIVE RESEARCH IN ELECTRICAL, ELECTRONICS, INSTRUMENTATION AND CONTROL ENGINEERING Vol. 4, Issue 2, February 2016

To design PI controller for the CTS, Integral of square error (ISE) is used as the rate function, which has to be reduced by the optimal collection of the controller parameters. In the recommended PSO method each particle has two members $\mathrm{K}_{\mathrm{c}}$ and $\mathrm{K}_{\mathrm{i}}$. It means that the search space has two aspect and origins must 'fly' in a two dimensional space. Just before control the process variables in CTS, according to the trials, the following PSO parameters in Table 2 are used.

Table 2. Parameters of PSO algorithm

\begin{tabular}{|l|c|}
\hline Population Size & 10 \\
\hline Number of Iterations & 50 \\
\hline $\mathrm{W}$ & 0.7 \\
\hline $\mathrm{c}_{1}$ & 1.5 \\
\hline $\mathrm{c}_{2}$ & 1.5 \\
\hline
\end{tabular}

\section{RESULTS AND DISCUSSION}

\section{A. Simulation of PI Controller}

The PI controller challenges to minimize the error by adjusting the controller output. The PI gain values are calculated by using the Z-N open loop tuning algorithm, response is shown in Fig 7

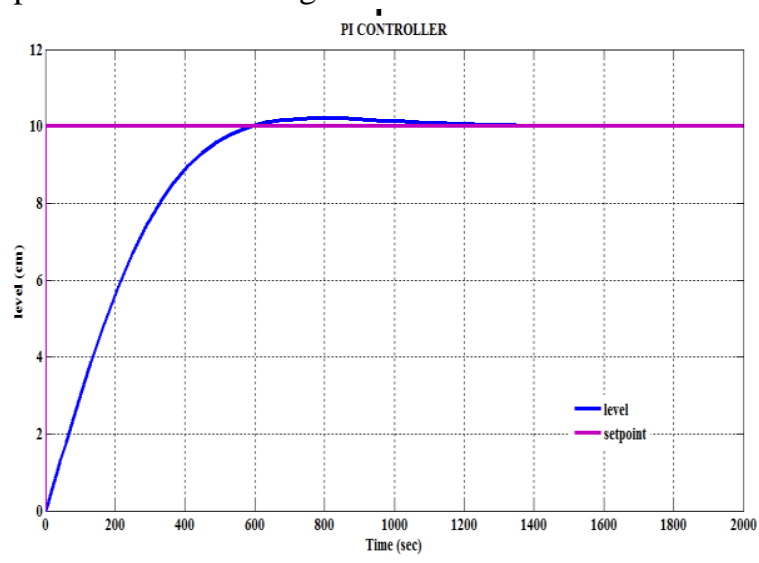

Fig. 7. response of PI controller

\section{B. Simulation of Internal Model Controller}

The closed loop response is obtained using the Internal Model Control (IMC).This improves the robustness of the system, the response using IMC is shown in Fig 8 .

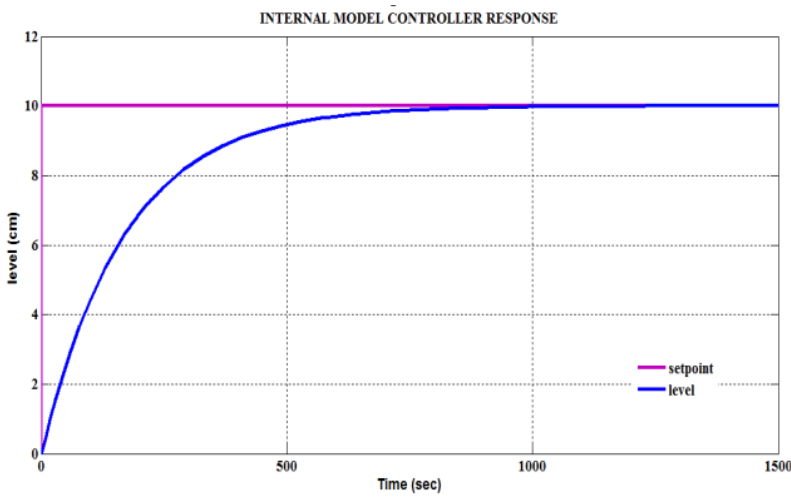

Fig. 8. Response of internal model controller

\section{Simulation of Optimal Controller}

The closed loop response is obtained using the optimal controller.This improves the robustness of the system, response using Optimal controller shown in Fig 9.

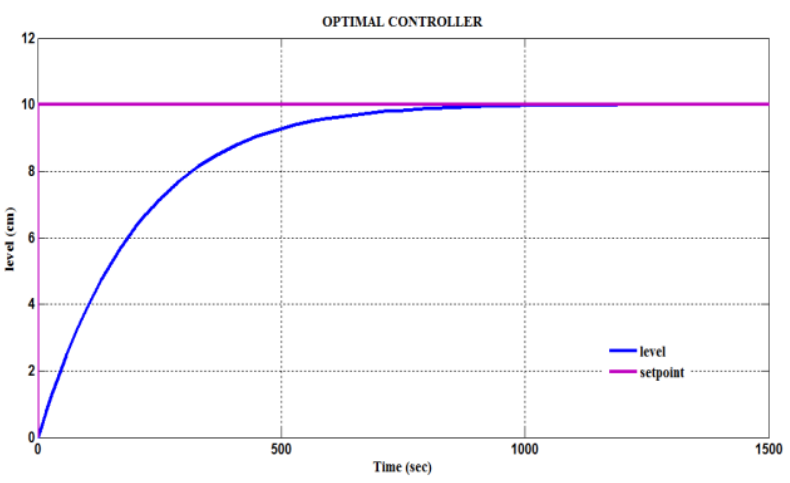

Fig. 9. Response of optimal selection of PI controller using PSO

\section{PERFORMANCE ANALYSIS}

The performance of the controllers are validated by comparing the settling time, rise time, peak overshoot and integral absolute error from the four different regions. The results are tabulated below in Table 3 .

Table 3. Performance analysis

\begin{tabular}{|l|l|c|c|c|c|}
\hline & & $\mathrm{h}=10 \mathrm{~cm}$ & $\mathrm{~h}=19 \mathrm{~cm}$ & $\mathrm{~h}=37 \mathrm{~cm}$ & $\mathrm{~h}=57 \mathrm{~cm}$ \\
\hline \multirow{2}{*}{$\begin{array}{l}\text { Rise time } \\
(\mathrm{sec})\end{array}$} & PI & 260 & 280 & 320 & 400 \\
\cline { 2 - 6 } & $\mathrm{IMC}$ & 450 & 420 & 370 & 490 \\
\cline { 2 - 6 } & PSO & 420 & 360 & 300 & 430 \\
\hline \multirow{2}{*}{$\begin{array}{l}\text { Settling } \\
\text { time } \\
(\text { sec })\end{array}$} & PI & 1800 & 1650 & 1550 & 1560 \\
\cline { 2 - 6 } & $\mathrm{IMC}$ & 1250 & 1200 & 1220 & 1260 \\
\cline { 2 - 6 } & PSO & 1100 & 1010 & 950 & 980 \\
\hline \multirow{2}{*}{$\begin{array}{l}\text { Peak over } \\
\text { Shoot } \\
(\%)\end{array}$} & PI & 1.2 & 1.2 & 1.2 & 1.2 \\
\cline { 2 - 6 } & $\mathrm{IMC}$ & 0 & 0 & 0 & 0 \\
\cline { 2 - 6 } & PSO & 0 & 0 & 0 & 0 \\
\hline $\begin{array}{l}\text { Integral } \\
\text { absolute } \\
\text { error }\end{array}$ & PI & 256 & 256 & 256 & 256 \\
\cline { 2 - 6 } & $\mathrm{IMC}$ & 194.6 & 194.6 & 194.6 & 194.6 \\
\cline { 2 - 6 } & PSO & 161 & 161 & 161 & 161 \\
\hline
\end{tabular}

From the Table it is clear that PSO tuned PI controller produces the better performances in simulation compared to other controllers.

\section{CONCLUSION AND FUTURE SCOPE}

\section{A. Conclusion}

The controlling of nonlinear process is a inspiring job. In this project, the PI and IMC controllers are designed in such a way that the system is physically reachable. But due to the presence of rise time and settling time, the performance of the system is affected. To avoid that optimal selection of PI using particle swarm optimization technique is implemented in simulation. In simulation optimal selection of PI using particle swarm optimization technique gives the better performance.

\section{B. Future Scope}

This project can be extended to implement the particle swarm optimization technique with the advanced controller by tuning its parameters to give a better performance

\section{REFERENCES}

[1] Abhishek Sharma and Nithya Venkatesan (2013), 'Comparing PI controller Performance for Non Linear Process Model', 
International Journal of Engineering Trends and Technology, Vol.4, No.3, pp.242-245.

[2] Angeline Vijula D. and Vivetha K. (2014), ' Model based Controller Design for Conical Tank System', International Journal of Computer Applications, Vol.85,No.12,pp.8-11.

3] Bhuvaneswari 1N.S. and Uma G. (2009), 'Adaptive and Optimal Control of a Non- Linear Process using Intelligent Controllers' ,Applied soft computing, Elsevier, Vol.9, No.1, pp.182-19.

[4] Dhanalakshmi R. and Vinodha R.(2013), ' Design of Control Schemes to Adapt PI Controller for Conical Tank Process',International journal of advanced soft computing applications, Vol.5, No.3,pp.1-20.

[5] George Stephanopoulos (1984), 'Chemical Process Control',Prentice-Hall publication, New Jersey, Eastern Economy Edition.

[6] Kala H. and Aravind P. (2013), 'Comparative Analysis of different Controller for a Nonlinear Level Control Process' Proceedings of IEEE Conference on Information and Communication Technologies,Vol.4,No.6, pp.724-729.

[7] Indhumathi K, Angeline Vijula D,(2014), 'design of model reference adaptive controller for conical tank system', International Journal of innovative research technology Vol. 1 No.7, pp. 457 461.

[8] Kala H,Aravind P, Valluvan,(2013) 'Comparative Analysis of Different Controller for a Nonlinear Level Control Process', Institute of Electrical and Electronics Engineers, Vol.5, No.1, pp. 1025-1031.

[9] Lakshmi,k.v, srinivas.p (2015),'optical tuning of PID controller using particle swarm optimization', IEEE,Vol.7, No.6, pp.1-5.

[10] SatheesKumar J and SatheeshKumar (2010), 'Modelling and Implementation of LabVIEW Based Non-linear PI Controller forConical Tank', Journal of Control \& Instrumentation Vol.1, No.1, pp.1-9.

[11] Sowmyal P. and Srivignesh N. (2012), 'A Fuzzy Control Scheme for Nonlinear Process', Proceedings of InternationalConference on Advanced Engineering Science and Management ,Vol.2,No.6, pp.683-687.

[12] Thirusakthimurugan ,Marshiana (2012). ' Design of Ziegler NicholsTuning Controller for a Non linear System', Proceedings of International Conference on Computing and Control Engineering , Vol.1,No.3,pp.121-124.

[13] Vijayalakshmi ,Dr.D.Manamalli,G. Palanikumar, (2013),'Experimental Verification of LPV Modeling and Control for Conical Tank System', Institute of Electrical and Electronics Engineers Vol.4, No.9, pp. 529-533. 